$\underline{\text { Demetrio Casado }^{1}}$

\title{
La ley de Promoción de la Autonomía Personal y atención a las personas en situación de dependencia y su contexto de medidas públicas ${ }^{2}$
}

SUMARIO: I. INTRODUCCIÓN SOBRE LOS OBJETIVOS DE LA LAAD. 1. MEDidas relativas a la ayuda propia y familiar. 2. Prestaciones monetarias de la Seguridad Social. 3. Medidas laborales. 4. Accesibilidad y ayudas técnicas no sanitarias. 5. Acción sanitaria. 6. Servicios sociales. II. BIBLiOGRAFÍA Y FUENTES.

\section{INTRODUCCIÓN SOBRE LOS OBJETIVOS DE LA LAAD}

La Ley 39/2006, de 14 de diciembre, de Promoción de la Autonomía Personal y Atención a las Personas en Situación de Dependencia (LEPA en adelante) compromete, desde su propio título, dos objetivos. Esta exposición presenta una reseña no exhaustiva de las medidas públicas anteriores a la LEPA relativas a ambos. La opción selectiva viene impuesta por la vastedad de la materia.

${ }^{1}$ Director del Seminario de Intervención y Políticas Sociales (SIPOSO).

2 Recibí muy valiosas observaciones de Manuel Aznar López y de Antoni Vilà. 
La LEPA entiende por autonomía: "la capacidad de controlar, afrontar y tomar, por propia iniciativa, decisiones personales acerca de cómo vivir de acuerdo con las normas y preferencias propias así como de desarrollar las actividades básicas de la vida diaria" (art. 2.1). De este modo, el objetivo de promoción de la autonomía personal abarca una faceta moral - la capacidad de decidir - y otra funcional — la capacidad de realizar actividades —.

El término "dependencia" es un sustantivo verbal, de modo que tiene tantos significados como relaciones de necesidad puedan darse. En el léxico de la intervención y las políticas sociales, ese término ha venido denotando sobre todo la pasividad económica relacionada con la percepción sin contrapartidas de ayudas o prestaciones materiales. Más recientemente, se prodigó también esa palabra para designar la vinculación psicobiológica a ciertas drogas adictivas. La LEPA define la dependencia como: "El estado de carácter permanente en que se encuentran las personas que, por razones derivadas de la edad, la enfermedad o la discapacidad, y ligadas a la falta o a la pérdida de autonomía física, mental, intelectual o sensorial, precisan de la atención de otra $\mathrm{u}$ otras personas o ayudas importantes para realizar actividades básicas de la vida diaria o, en el caso de las personas con discapacidad intelectual o enfermedad mental, de otros apoyos para su autonomía personal.” (art. 2.2). La LEPA opta, pues, por la dependencia funcional.

Por el objeto de esta exposición, la reseña de las disposiciones de la LAAD se limitará a las reguladoras de prestaciones.

\section{MEDIDAS RELATIVAS A LA AYUdA PROPIA Y FAMILIAR}

Es muy potente la imagen pretérita de provisión de asistencia a "incurables", "decrépitos", "imposibilitados" e "impedidos" en centros residenciales de carácter benéfico, sin aportaciones de los interesados o de sus familiares. Pero la frecuencia relativa de tales casos era pequeña; y es muy rara en el presente. En primer lugar, la mayor parte de los afectados de dependencia funcional residen en domicilios particulares propios o de familiares, como muestran las cifras siguientes. Según las Estadísticas de Establecimientos Sanitarios en régimen de internado del Ministerio de Sanidad y Consumo, para 2001, los hospitalizados de larga estancia representaban menos del 1\% de la población afecta de dependencia. A partir de información obtenida por el Instituto Nacional de Estadística en 1999, se ha estimado que los residentes en establecimientos de servicios sociales representaban en torno al 10\% de los afectos de dependencia (Rodríguez Cabrero, 2004: 58). Quede indicado de paso que la opción por le domicilio privado goza de amplio aprecio al menos entre la población de edad avanzada (Ministerio de Traba- 
jo y Asuntos Sociales, 2005: 203). Preferencia ésta que, por lo demás, coincide con el criterio técnico actual (Rodríguez RodríGuez, 2006: 52) y resulta económicamente conveniente para el Estado social. En segundo lugar, son muchas las aportaciones —en dinero y gestión - de los propios afectados para su asistencia y es pauta mayoritaria la provisión de ayudas por parte de sus familiares. Éstos cooperan de varios modos: asistencia de mantenimiento directa o mediante servidores domésticos en el domicilio común; asistencia circunstancial presencial y a distancia cuando el afectado reside en domicilio propio y distinto; apoyo personal y/o económico para el acceso a servicios complementarios o sustitutorios del particular; etc. Por lo indicado, resulta oportuno comenzar esta exposición por las medidas públicas relativas a la contribución de los propios interesados a la atención de su dependencia y a la ayuda de familiares.

En el campo doméstico, la medida pública más tradicional se refiere a la ayuda familiar. El Código Civil provee a la atención de las situaciones de dependencia funcional - y a la económica - tanto de la infancia como de la población que interesa en esta exposición y lo necesite, mediante el llamado derecho de alimentos (título VI). El mismo incluye prestaciones materiales y personales. Están obligados a proveerlas los cónyuges, los ascendientes y descendientes, y los hermanos bajo cierta condición. La ayuda personal cubierta por el derecho de alimentos puede ser provista: de modo directo, mediante la prestación de pensiones, mediante la contratación de servidores domésticos y recurriendo a servicios. Esta última posibilidad ha dado pie a que algunas normas reguladoras del régimen de acceso y económico a y de servicios sociales públicos hayan incluido la exigencia de copago a los familiares en virtud de las obligaciones derivadas del derecho de alimentos (VILÀ, 2004: 141 y 142).

En la mayor parte de los casos, el derecho de alimentos se satisface espontáneamente, sin necesidad de invocarlo. Y resulta muy lamentable la necesidad de hacerlo. El derecho de alimentos, como las otras medidas públicas relativas a la solidaridad familiar, es compatible con el Estado social concebido como recurso, no sustitutorio de aquella, sino corrector de sus limitaciones y desigualdades.

La Ley 41/2003, de 18 de noviembre, de Protección Patrimonial de las Personas con Discapacidad establece medidas favorecedoras de la solidaridad familiar. Aparte de las orientadas expresamente al objeto que indica el título de la norma, cabe mencionar la modificación (mediante el art. 12) del Código Civil en materia del contrato de alimentos, por el cual "una de las partes se obliga a proporcionar vivienda, manutención y asistencia de todo tipo a una persona durante su vida, a cambio de la transmisión de un capital en cualquier clase de bienes y derechos" (art. 1791). 
La política fiscal viene adoptando numerosas y diversas medidas reguladoras de beneficios fiscales en favor de las personas con discapacidades (Rodríguez Márquez y Ruiz Hidalgo, 2004). Algunos de tales beneficios inciden indirectamente en dichas personas; tal es el caso de las concernientes a las entidades no lucrativas y las medidas fiscales incentivadoras del mecenazgo. Los que favorecen directamente a las economías de las personas con discapacidad se incluyen en la normativa de los impuestos sobre las rentas de las personas físicas (IRPF), sobre sociedades, trasmisiones patrimoniales, valor añadido, de la Administración Local, adquisición de vehículos en función de problemas de movilidad, etc. De ellas, por su obvia importancia, se reseñan y valoran seguidamente las del IRPF. La regulación vigente del mismo fue establecida por la Ley 35/2006 de 28 de noviembre, del Impuesto sobre la Renta de las Personas Físicas y de modificación parcial de las leyes de los Impuestos sobre Sociedades sobre la Renta de no Residentes y sobre el Patrimonio. Son muy numerosas las medidas de dicha norma relativas a la discapacidad y todas ellas alcanzan a la dependencia funcional, supuesto que sus ámbitos subjetivos sólo se acotan por los grados menores de afectación, nunca por los mayores. Por esto y en aras de la brevedad, la reseña que sigue no será exhaustiva, sino selectiva.

Veamos primero las exenciones. La Ley del IRPF exime de fiscalidad: a las prestaciones y pensiones públicas por la condición de víctima de actos de terrorismo; a las prestaciones que el contribuyente recibe de la Seguridad Social o de entidades que la sustituyan por incapacidad permanente absoluta y gran invalidez — esta última equivalente a dependencia funcional—; a las prestaciones económicas públicas por acogimiento de personas con discapacidad; las ayudas económicas públicas por discapacidad con un grado igual o superior al 65\% para financiar la estancia en residencias o centros de día; las prestaciones económicas de la LEPA (art. 7.a, f, i, y x).

La Ley de IRPF aplica también la técnica de la reducción de las rentas para la determinación de la renta gravable. Para las percepciones por situaciones entre las que se incluye la dependencia funcional dicha reducción será del 40\%: pensiones y haberes pasivos percibidos de la Seguridad Social, clases pasivas y demás prestaciones públicas por incapacidad; prestaciones de mutualidades generales obligatorias de funcionarios, colegios de huérfanos y otras entidades similares (arts. 17 y 18). Además, se minoran los rendimientos del trabajo como trabajadores activos de las personas con discapacidad; la cuantía de la minoración es superior para las situaciones de más graves (art. 20).

En la regulación de la base liquidable, la Ley del IRPF establece reducciones por atención a situaciones de dependencia y envejecimiento. Abarcan aquélla estos supuestos: aportaciones y contribuciones a sistemas de 
previsión social constituidos a favor de personas con discapacidad (art. 53); aportaciones a patrimonios protegidos de las personas con discapacidad (art. 54).

La regulación de los mínimos de la base liquidable que, por circunstancias personales y familiares, no se somete a tributación incluye medidas que alcanzan a la dependencia funcional. La Ley beneficia a las situaciones de discapacidad de los descendientes (art. 58), de los ascendientes (art. 59) y del contribuyente, en este caso cuando aquella suponga un grado de minusvalía igual o superior al 65\% (art. 60).

La Ley del IRPF, en la determinación de la cuota líquida, contempla también la discapacidad del contribuyente, así como de su cónyuge y parientes próximos en la regulación de las deducciones por inversión en la vivienda habitual (art. 68.1.4. ${ }^{\circ}$ ).

La política de beneficios fiscales es muy fácil de regular y de gestionar, esto último en razón de que no requiere montar y mantener organismos de administración ad hoc, con esta salvedad: los beneficios por discapacidad incrementan la demanda de valoraciones de la misma. Desde el punto de vista de la equidad, es positivo el trato favorable que la Ley del IRPF hace, en general, de las situaciones de discapacidad más graves. En el platillo de los inconvenientes, es obvia la limitación de las medidas fiscales para alcanzar la universalidad y la progresividad, tan importantes en las políticas sociales. Es conocido que la red fiscal no alcanza —al menos de modo relevante- a los individuos más pobres, en cuanto que sus ingresos, operaciones de ahorro, consumos e inversiones son de muy poca monta y en no pocos casos sin control público.

La LEPA regula un mixto de recursos para facilitar la provisión de cuidados en el medio doméstico: la prestación económica para cuidados en el entorno familiar y apoyo a cuidadores no profesionales (art. 18). La percepción de esa prestación económica entraña el derecho y la obligación de la integración del cuidador en la Seguridad Social. La Ley establece que el apoyo a los cuidadores no profesionales se realice mediante "programas de formación, información y medidas para atender periodos de descanso".

La prestación económica para cuidados en el entorno familiar es muy adecuada para paliar los costes de oportunidad de ganancia que lleva consigo muy frecuentemente esa clase de atención. La integración en la Seguridad Social sirve para evitar situaciones de desventaja en la protección social. Siendo que la permanencia en los domicilios privados es deseable, y sin desconocer el papel que juegan al efecto ciertos servicios formales (teleasistencia, ayuda adomicilio, centros de día, estancias temporales en residencias), parece inconveniente el carácter excepcional que la Ley asigna a esta prestación. En cuanto a las medidas de apoyo a los cuidadores no profesio- 
nales, la LEPA sólo aporta un compromiso de promoción. No cabe, pues, anticipar valoración alguna. Sí cabe desear que en los programas de apoyo a los cuidadores, para los familiares, se procure conciliar la capacitación técnica con la conservación del componente afectivo y del sentido de reciprocidad propios de la ayuda familiar para las situaciones de dependencia.

La LEPA trae una posibilidad nueva para facilitar la autogestión de la ayuda funcional para situaciones de dependencia: la prestación económica de asistencia personal (art. 19). La misma está destinada a financiar la contratación de esa clase de servicio por el propio beneficiario, con objeto de recibir ayuda para su acceso a la educación y el trabajo, y para el ejercicio de actividades básicas de la vida diaria.

El régimen de la prestación económica de asistencia personal es muy favorable para: lograr una asistencia adaptada a las necesidades del contratante, posibilitar la permanencia en el propio medio, facilitar la participación social del afectado, conservar su autonomía de decisión.

La LEPA aborda la importante cuestión de la autofinanciación de los apoyos requeridos por la dependencia funcional comprometiendo la regulación de la cobertura privada de la dependencia y la cofinanciación de los servicios regulados por la nueva Ley (disposición adicional séptima). Este mandato ha sido cumplido mediante Ley 41/2007, de 7 de diciembre, por la que se modifica la Ley 2/1981, de 25 de marzo, de Regulación del Mercado Hipotecario y otras normas, que aporta dos novedades importantes para el objeto que aquí interesa. En primer lugar, la hipoteca inversa (disposición adicional primera). La misma consiste en "el préstamo o crédito garantizado mediante hipoteca sobre un bien inmueble que constituya la vivienda habitual del solicitante." Éste, o los beneficiarios que pueda designar, han de ser "personas de edad igual o superior a 65 años o afectadas de dependencia severa o gran dependencia". Es importante notar que la Ley posibilita el uso de la vivienda hasta el fallecimiento del prestatario o, si así se acuerda contractualmente, del último de los beneficiarios. La vivienda hipotecada puede ser rescatada por los herederos. La Ley establece reducciones importantes en los costes de formalización de la hipoteca. Posibilita la norma la hipoteca inversa de otros bienes inmuebles distintos de la vivienda habitual del solicitante; para este supuesto no son aplicables las indicadas reducciones. Por otra parte, la Ley 41/2007 regula el aseguramiento privado de la dependencia (disposición adicional segunda). El mismo podrá hacerse mediante contratos de seguro con entidades aseguradoras y mutualidades de previsión social, así como a través de un plan de pensiones.

La hipoteca inversa sólo es posible para los titulares de su vivienda, pero esta circunstancia se da en muchos casos. Para ellos, el nuevo recurso 
parece muy interesante, por la adaptación de su régimen a las circunstancias e intereses de los destinatarios del mismo. Los seguros de dependencia sólo ofrecen interés a quienes pueden financiarlos. Pero es muy amplio el sector de población que puede hacerlo, y parece una previsión conveniente para una gran parte del mismo. Ello deriva de que la LEPA no cubre la totalidad de las necesidades derivadas de las situaciones de dependencia, especialmente para los afectados de clases medias y altas. Tal limitación viene de estas características de la acción protectora de la LEPA: 1) la utilización de los servicios lleva aparejado el copago de su coste, en función de los niveles de capacidad económica del beneficiario determinados reglamentariamente; 2) las prestaciones monetarias son de cuantía limitada, que se reduce en función de dicha capacidad económica del beneficiario.

\section{Prestaciones monetarias de la Seguridad Social}

Las prestaciones monetarias son un medio muy importante de apoyo a la ayuda autogestionada y a la familiar, si bien pueden aplicarse igualmente a la financiación de bienes — como ayudas técnicas, por ejemplo- o servicios determinados relativos a la dependencia funcional. La Seguridad Social dispensa la inmensa mayoría de esta clase de prestaciones. En sus inicios (Aznar López, 1999: 178 y 179), la acción protectora de los seguros sociales relativa a la dependencia alcanzaba una parte relativamente pequeña de la población; en la actualidad, por el contrario, su ámbito subjetivo es ampliamente mayoritario. La Ley General de la Seguridad Social (LGSS en adelante), cuyo texto refundido fue aprobado por el Real Decreto Legislativo 1/1994, de 20 de junio, es la norma central de dicha institución. La misma regula el Régimen General de la Seguridad Social (título II), que abarca prestaciones contributivas y no contributivas.

La acción protectora de la Seguridad Social contributiva mediante prestaciones para asistencia de mantenimiento en situaciones de dependencia funcional se ha desarrollado tomando como objeto la contingencia que en la Ley 193/1963, de 28 de diciembre, de Bases de la Seguridad Social se denomina "gran invalidez" (base octava). La misma es definida por la LGSS en estos términos: "Se entenderá por gran invalidez la situación del trabajador afecto de incapacidad permanente y que, por consecuencia de pérdidas anatómicas o funcionales, necesite la asistencia de otra persona para los actos más esenciales de la vida, tales como vestirse, desplazarse, comer o análogos.” (art. 137.6). La prestación para la gran invalidez consiste en un "complemento, destinado a que el inválido pueda 
remunerar a la persona que le atienda" no menor del $45 \%$ de la pensión que corresponda por incapacidad permanente total o absoluta (art. 139.4). (La gran invalidez es circunstancia que tiene en cuenta la LGSS al regular las prestaciones por muerte y supervivencia; las mismas quedan fuera de esta exposición por no tener relación con la acción protectora de la LAAD).

Al margen de la Seguridad Social contributiva, se regularon prestaciones destinadas a situaciones no específicas de dependencia funcional pero abarcadoras de la misma: 1) auxilios de vejez y enfermedad del Fondo Nacional de Asistencia Social (FONAS) — creado por Ley 45/1960, de 21 de julio-; 2) ayudas para afectados por el síndrome tóxico, cuya protección fue regulada por el Real Decreto 2.448/1981, de 19 de octubre; 3) subsidios de garantía de ingresos mínimos y por ayuda de tercera persona creados por la Ley 13/1982, de Integración Social de los Minusválidos (LISMI) (arts. 14 a 16). La Ley 26/1990, de 20 de diciembre, por la que se establecen prestaciones no contributivas en la Seguridad Social dio un gran paso en el camino de la universalización protectora de aquella institución y, aparte de otros cambios, vino a ocupar el espacio protector de las prestaciones citadas. Esto a salvo de, por una parte, la vigencia temporal de las prestaciones del FONAS (Alonso Seco y Gonzalo González, 1997: 418 y 419) y, por otra, del régimen transitorio de las de la LISMI regulado por el Real Decreto Legislativo 1/1994 ya citado (disposición transitoria undécima). En lo que interesa aquí, a la protección de la gran invalidez del trabajador se sumó la del adulto de edad entre 18 y 65 años afecto de minusvalía de grado igual o superior al $75 \%$ y necesidad de ayuda para los actos esenciales de la vida, sin derecho al complemento de la Seguridad Social contributiva y con bajo nivel de ingresos. La prestación consistía en un complemento del $50 \%$ sobre la pensión no contributiva unificada de invalidez. Esta protección está incluida en la LGSS (arts. 144 y 145).

Las prestaciones familiares de la Seguridad Social han dado ocasión para la regulación de modalidades de las mismas diferenciadas en función de situaciones de dependencia funcional. La protección para beneficiarios de la Seguridad Social contributiva vino a ser doblada también por la Ley 26/1990, de 20 de diciembre, antes citada. En la LGSS vigente, toda la protección familiar que interesa a esta exposición es de carácter contributivo y uniforme. La relativa a situaciones de dependencia funcional consiste en una asignación unificada para los casos de hijos a cargo mayores de 18 años y con un grado de minusvalía igual o superior al 75\% y necesidad de "concurso de otra persona para realizar los actos más esenciales de la vida" (art.182 bis.c). 


\section{TABLA 1}

PRESTACIONES MONETARIAS DE LA SEGURIDAD SOCIAL POR DEPENDENCIA FUNCIONAL

\begin{tabular}{|c|c|c|c|c|}
\hline CONTINGENCIAS & $\begin{array}{c}\text { CALIFICACS. } \\
\text { ADMINS. } \\
\text { HABILITS. }\end{array}$ & $\begin{array}{l}\text { PRESTACS. POR } \\
\text { DEPENDENCIA }\end{array}$ & FINANCIACIÓN & $\begin{array}{l}\text { RÉGIMENES DE } \\
\text { DISPENSACIÓN }\end{array}$ \\
\hline $\begin{array}{l}\text { 1. Dependencia en } \\
\text { hijos hasta } 18 \text { años }\end{array}$ & & $\begin{array}{l}\text { Asignación no } \\
\text { diferenciada de } \\
\text { la relativa a } \\
\text { minusvalía }\end{array}$ & & \\
\hline $\begin{array}{l}\text { 2. Dependencia de } \\
\text { hijos mayores de } 18 \\
\text { años, sean sus padres } \\
\text { beneficiarios o no de } \\
\text { la Seguridad Social } \\
\text { contributiva }\end{array}$ & $\begin{array}{l}\text { Minusvalía- } \\
\text { dependencia }\end{array}$ & $\begin{array}{l}\text { Asignación } \\
\text { económica } \\
\text { unificada }\end{array}$ & Fiscal & $\begin{array}{l}\text { Requisito de } \\
\text { ingresos más } \\
\text { calificación }\end{array}$ \\
\hline $\begin{array}{l}\text { 3. Dependencia } \\
\text { ocurrida antes de la } \\
\text { edad de jubilación en } \\
\text { adultos incluidos en } \\
\text { el Régimen General } \\
\text { de la SS }\end{array}$ & $\begin{array}{l}\text { Gran } \\
\text { invalidez }\end{array}$ & $\begin{array}{l}=>45 \% \text { de la } \\
\text { pensión } \\
\text { variable de } \\
\text { incapacidad }\end{array}$ & Contributiva & $\begin{array}{l}\text { Requisito de } \\
\text { cotización y } \\
\text { mediante } \\
\text { calificación }\end{array}$ \\
\hline $\begin{array}{l}\text { 4. Idem después de la } \\
\text { edad de jubilación }\end{array}$ & & No & & \\
\hline $\begin{array}{l}\text { 5. Dependencia } \\
\text { ocurrida en adultos } \\
\text { de entre } 18 \text { y } 65 \text { años } \\
\text { sin derecho a } \\
\text { pensión contributiva }\end{array}$ & $\begin{array}{l}\text { Minusvalía- } \\
\text { dependencia }\end{array}$ & $\begin{array}{l}50 \% \text { de la } \\
\text { pensión } \\
\text { unificada de } \\
\text { invalidez }\end{array}$ & Fiscal & $\begin{array}{l}\text { Requisito de } \\
\text { ingresos y } \\
\text { calificación }\end{array}$ \\
\hline $\begin{array}{l}\text { 6. Idem después de } \\
\text { los } 65 \text { años }\end{array}$ & & No & & \\
\hline
\end{tabular}

La tabla incluye un resumen de la estructura protectora de la dependencia funcional por el Régimen General de la Seguridad Social, con indicación de sus sectores subjetivos no protegidos. La situación puede sintetizarse también así:

- La dependencia de la población menor de 18 años no cuenta con una protección específica para la dependencia superior a la establecida por minusvalía, pese a que aquella puede generar necesidad de ayuda personal para, por ejemplo, actividad tan importante como el desplazamiento al centro de estudios. Sí están protegidos los hijos mayores de 18 años. 
- La población trabajadora dispone de protección. De la población adulta no trabajadora de 18 a 65 años sólo están protegidos los que carecen de recursos económicos. Esta exigencia puede dar lugar a situaciones de dificultad importantes en las clases medias bajas.

- La población beneficiaria de prestaciones por dependencia funcional seguirá percibiéndolas tras cumplir 65 años. Los que resulten afectados por dicha contingencia tras cumplir esa edad no tienen derecho a una protección específica, lo cual constituye un obvio problema de desprotección y de discriminación por edad.

A efectos de las prestaciones por familia numerosa, los hijos con minusvalía se computan doble (art. 185.1), pero la LGSS no diferencia el supuesto de la dependencia funcional.

Los regímenes especiales de la Seguridad Social, con algunas variaciones en su regulación, incluyen en sus tablas de contingencia la "gran invalidez" y le dispensan protección específica. Lo mismo cabe decir, en términos generales, de la prestación familiar para situaciones de dependencia. El Seguro Escolar cubre también las situaciones de dependencia, pero la cuantía de sus prestaciones monetarias es muy baja.

Las intervenciones de prevención primaria, rehabilitación e integración no suelen orientarse exclusivamente a tal o cual grado de discapacidad. Hecha esta salvedad, quede nota de dos cambios relativos a prestaciones activas en la LGSS. La Ley 39/1999 establece la inclusión en la LGSS (título II, capítulo IV ter) de disposiciones que regulan una nueva prestación económica para el tiempo de suspensión del contrato por riesgo para el embarazo (art. 14). Mediante la Ley Orgánica 3/2007, de 22 de marzo (disposición adicional decimoctava), se modifica la regulación de dicha protección y se extiende a la lactancia natural (arts. 134 a 135-ter de la LGSS). Es antecedente básico de estas medidas la Ley 31/1995, de 8 de noviembre, de Prevención de Riesgos Laborales, que establece el derecho de suspensión de contrato de la mujer trabajadora embarazada o lactante cuando su puesto de trabajo entrañe riesgos para su estado o función y no resulte posible su integración en otro sin tal inconveniente. La protección de la Seguridad Social consiste en un subsidio paliativo de la pérdida de salario derivada de la suspensión del contrato. Se trata, pues, de una de las piezas de esa medida de prevención de riesgos para la salud, que en algún caso podría abocar a situaciones de dependencia funcional. El segundo cambio es de signo contrario: por la Ley 52/2003, de 10 de diciembre, se derogaron las disposiciones de dicha norma reguladoras de la recuperación.

Los regímenes especiales de la Seguridad Social, en general y con algunas variaciones en su regulación, incluyen prestaciones monetarias por suspensión de contrato de la mujer trabajadora embarazada o lactante. 
Al margen de la Seguridad Social, la Ley 32/1999, de solidaridad con las víctimas del terrorismo estableció, además de otras medidas, indemnizaciones para varias contingencias, la gran invalidez entre ellas (art. 6.1).

La LEPA instituye tres prestaciones económicas — según su léxico- - La "prestación económica vinculada al servicio" (art. 17) que, como indica su propio enunciado, está vinculada a la adquisición de una prestación técnica; se reseñará junto con los servicios. La "prestación económica para cuidados en el entorno familiar" (art. 18) es análoga a las monetarias de la Seguridad Social; por su función, fue reseñada al tratar de la autoayuda y la ayuda familiar. La "prestación económica de asistencia personal" (art. 19), como la primera, está afectada a la financiación de una prestación técnica, si bien la misma no es provista por una organización sino por un asistente empleado del beneficiario; por su aplicación, fue reseñada también al tratar de la autoayuda y la ayuda familiar.

Quede nota, finalmente, de dos disposiciones adicionales de la LEPA (novena y decimosexta) relacionadas con la Seguridad Social. En primer lugar (disposición adicional novena), la Ley prevé la convalidación de los reconocimientos de la gran invalidez y de la necesidad de asistencia de tercera persona. En segundo lugar (disposición adicional decimosexta), se establece un cambio en la regulación de la LGSS del cálculo de la cuantía de las prestaciones de invalidez en su modalidad no contributiva (art. 145.2).

\section{Medidas laborales}

La permanencia en domicilios particulares de las personas afectas de dependencia viene posibilitada o facilitada tradicionalmente -y con tendencia de aumento- por la contratación de servidores domésticos. La misma ha de hacerse de acuerdo con el Real Decreto 1424/1985, de 1 de agosto, por el que se regula la relación laboral de carácter especial del Servicio del Hogar Familiar. Su ámbito de aplicación (art. 1) abarca desde las tareas domésticas hasta los cuidados personales, de modo que da cobertura a las necesidades básicas derivadas de la dependencia, tanto de la primera edad como de la ocasionada por enfermedades y/o deficiencias.

Pese a la baja exigencia para el empleador de la norma citada, con mucha frecuencia se opta por la contratación irregular. La débil posición de mercado de una gran parte de la población inmigrante, entre otros factores, lo facilita.

El servicio doméstico es un recurso sólo asequible a una parte de la población. Sólo un porcentaje pequeño de los trabajadores que lo prestan tiene capacitación para las atenciones especiales que requieren ciertas situaciones 
de deficiencias, como las generadas por enfermedades neuromusculares o demencias. En el lado positivo: el servicio doméstico es muy funcional como complemento de la atención de familiares; el recurso al mismo alivia la presión sobre la oferta pública de protección.

La LEPA aporta una novedad conexa con la clase de recurso reseñado al regular la prestación económica de asistencia personal (art. 19) que tiene el objetivo de coadyuvar a la contratación de aquella. Ya quedó reseñada y valorada al hablar de la ayuda propia y familiar.

A partir del impulso de la Unión Europea, ha venido a ser objeto de atención creciente la atención pública a la conciliación de la provisión de cuidados familiares con la actividad laboral de los dispensadores - dispensadoras, en la mayor parte de los casos- de aquellos. Dicha política no es privativa de las situaciones de dependencia funcional, pero las abarca y aun las tiene en cuenta en cuanto tales o haciendo parte de las de discapacidad, en general.

Se abordó de modo sistemático la citada línea política mediante la Ley 39/1999, de 5 de noviembre, para promover la conciliación de la vida familiar y laboral de las personas trabajadoras. Esta norma incluye medidas facilitadoras de la provisión de cuidados familiares a personas dependientes, tanto por minoría de edad como por déficit funcionales. Dichas medidas son incorporadas al Estatuto de los Trabajadores (arts. 37.5, 46.3 y 48). Se prevé la reducción de jornada para dos supuestos (art. 2.2). Por una parte establece que "Quien por razones de guarda legal tenga a su cuidado directo algún menor de seis años o un minusválido físico, psíquico o sensorial, que no desempeñe una actividad retribuida, tendrá derecho a una reducción de la jornada de trabajo, con la disminución proporcional del salario, entre, al menos, un tercio y un máximo de la mitad de la duración de aquella." En segundo lugar, la Ley habilita la reducción de jornada a "quien precise encargarse del cuidado directo de un familiar, hasta el segundo grado de consanguinidad o afinidad, que por razones de edad, accidente o enfermedad no pueda valerse por sí mismo, y que no desempeñe actividad retribuida." La excedencia por cuidado de familiares es prevista por la Ley 39/1999 (art. 4) para dos supuestos también. El primero se refiere a los hijos y el segundo, de especial interés para esta exposición, contempla el "cuidado de un familiar, hasta el segundo grado de afinidad, que por razones de edad, accidente o enfermedad no pueda valerse por sí mismo, y no desempeñe actividad retribuida"; se prevé excedencia por tiempo no superior a un año, salvo lo que pueda acordarse en negociación colectiva. Además, al modificar la norma de la suspensión de contrato con reserva de puesto de trabajo (art. 5), la Ley adopta el plazo más favorable para las adopciones y acogimientos de niños mayores de seis años afectos de discapacidad. 
La Ley 12/2001, de 9 de julio, de medidas urgentes de reforma del mercado de trabajo para el incremento del empleo y la mejora de su calidad modifica (disposición adicional octava) con sentido conciliador algunas disposiciones de la Ley del Estatuto de los Trabajadores (1) y de la Ley 30/1984, de 2 de agosto, de Medidas de Reforma de la Función Pública (2). Por una parte se habilitan permisos de una hora para los trabajadores y funcionarios padres de hijos nacidos prematuramente o que por cualquier causa deban permanecer hospitalizados. Además, para tales supuestos, se autoriza que la suspensión o permiso posterior al parto se computen a partir del alta hospitalaria. La Ley 51/2003, de 2 de diciembre, de igualdad de oportunidades, no discriminación y accesibilidad universal ratifica, mencionando expresamente el supuesto de discapacidad, la inclusión de la excedencia por cuidado de familiares en el Estatuto de los Trabajadores (disposición adicional primera).

La Ley Orgánica 3/2007, de 22 de marzo, para la igualdad efectiva de mujeres y hombres incidió en la política de conciliación mediante nuevas modificaciones (disposición adicional décima) de la Ley del Estatuto de los Trabajadores. Para las figuras reseñadas, se adoptan estos cambios: 1) ampliación de la posibilidad de graduar la reducción de jornada al rebajar su límite mínimo a un octavo (cinco); 2) incremento a dos años — salvo lo que pueda acordarse en negociación colectiva - del límite máximo de la excedencia para atender al cuidado de familiares (nueve); 3) fijación en trece semanas de la posible ampliación de la suspensión de contrato en casos de hospitalización neonatal por parto prematuro u otra causa; 4) adopción de un lapso adicional de dos semanas para la suspensión del contrato en casos de acogimiento o adopción de niños afectos de discapacidad. La Ley 3/2007 establece también medidas afines a las reseñadas para funcionarios y personal estatutario del sector público (disposiciones adicionales decimonovena a vigésimo tercera).

Las medidas de conciliación son un avance muy estimable, pero su alcance social es limitado. Sólo una parte de la población destinataria de las medidas arbitradas puede asumir la reducción o cese de ingresos. Debe, pues, proveerse a establecer los subsidios oportunos para la población de menores recursos económicos.

La LEPA no aborda la línea conciliatoria directamente. Pero cabe entender que la prestación económica para cuidados en el entorno familiar puede servir, en algún caso, para paliar la pérdida de salario por excedencia para ese mismo objeto.

Para terminar este apartado, recordemos que la Ley General de la Seguridad Social incluye estas dos medidas pro integración laboral de las personas afectas de dependencia funcional: 1) en la modalidad contributiva, compa- 
tibilidad de la percepción de la pensión con actividades lucrativas, incluso para la gran invalidez (art. 141.2); 2) en la modalidad no contributiva, posibilidad de recuperar el derecho a la pensión de invalidez que se hubiera interrumpido por alta en actividad laboral o equivalente (art. 144.1.d).

Las medidas pro integración laboral reseñadas son coherentes con el ideal de compatibilizar la protección y la participación social. La experiencia muestra, por lo demás, que en algunos casos de dependencia son aplicables.

Por su posible papel en la integración laboral del beneficiario, cabe relacionar con las medidas anteriores la prestación económica de asistencia personal de la LEPA (art. 19), antes reseñada.

\section{ACCESIBILIDAD y AYUdAS TÉCNICAS NO SANITARIAS}

Es factor importante para la permanencia de las personas afectas de dependencia funcional en domicilios privados la accesibilidad igualmente funcional de los mismos, incluyendo los espacios y elementos comunes de las fincas, en el caso de edificios de varias viviendas y urbanizaciones. Por supuesto, la residencia del afectado de dependencia funcional en domicilio particular en condiciones de normalidad -es decir, con posibilidades de desenvolvimiento en la sociedad-requiere también la accesibilidad: 1) de todos los edificios de uso privado o colectivo, en cuanto que puede ser usuario habitual (centro docente o laboral) o visitante ocasional; 2) del medio urbano, los trasportes y las telecomunicaciones. Las barreras funcionales son factores de generación o agravamiento de la dependencia. De este modo la accesibilidad: por una parte, facilita la autonomía funcional de las personas afectas de discapacidades; por otra, facilita la ayuda de los cuidadores de quienes la requieren - la inaccesibilidad funcional requiere esfuerzos adicionales y genera, no pocas veces, fatiga y aun lesiones-.

La accesibilidad pasiva, consistente en la ausencia de barreras físicas que dificulten la movilidad, es condición básica exigible a la edificación y a los entornos soporte de la vida social. La tecnología permite, además, la accesibilidad activa de los domicilios, de los edificios de uso colectivo, de los transportes y de las comunicaciones mediante la dotación de elementos destinados a facilitar el desenvolvimiento en ellos, como, por ejemplo: grúas para las operaciones de acceso al lecho y al baño; recursos domóticos para mover cortinas, abrir puertas, conectar y desconectar la radio o la televisión; teléfonos de marcaje asistido; plataformas elevadoras y ascensores; adaptaciones informáticas físicas y lógicas, etc.

Sin necesidad de recurrir a estudios especializados sabemos que la mera accesibilidad pasiva escasea en las viviendas españolas. No fue objetivo 
exigido ni valorado del diseño arquitectónico y urbanístico, de modo que la mayor parte del patrimonio arquitectónico y urbanístico se produjo con barreras. La promoción ideológica y técnica de la accesibilidad del medio físico se inicia en España en los años 70 del pasado siglo. En ese decenio se inicia también la oferta pública de ayudas a los particulares y a entidades asociativas en este campo. En el decenio siguiente, por Real Decreto 620/1981, de 5 de febrero, sobre régimen unificado de ayudas públicas a disminuidos se instituyen, entre otras, las aplicables a movilidad y transporte, incluyendo la adaptación de la propia vivienda (arts. 13 a 16). Las iniciativas pro accesibilidad continuaron con intensidad creciente. Actualmente, por el régimen de competencias, están interviniendo en materia de accesibilidad, por orden de protagonismo, las Comunidades Autónomas, los Municipios y el Estado Central. De las Comunidades Autónomas cabe destacar su acción legislativa. En los Municipios se viene produciendo un movimiento creciente de planes de accesibilidad. En cuanto al Estado central, parece estimable la acción que vienen realizando: 1) el INSERSOIMSERSO, especialmente mediante su Centro Estatal de Accesibilidad y Ayudas Técnicas; 2) el Real Patronato sobre Discapacidad, mediante un programa de reciclaje de profesionales. Por otra parte, se está produciendo la reglamentación de las disposiciones sobre accesibilidad establecidas mediante la Ley 51/2003, de 2 de diciembre, de igualdad de oportunidades, no discriminación y accesibilidad universal (art. 10 principalmente). En el sector privado, merece ser mencionada la producción por AENOR de un bloque apreciable de normas técnicas de accesibilidad en edificación y urbanismo.

La empresa de la accesibilidad funcional es inmensa y, además, difícil y costosa para una gran parte del patrimonio antiguo: sirva como ejemplo que en ciertas casas de pisos viejas no se puede instalar un ascensor de tamaño suficiente para ser usado con silla de ruedas, salvo instalándolo en el exterior del edificio. Y sabemos que una gran parte de la población de edad avanzada -entre la que la dependencia funcional presenta una prevalencia alta- se aloja en viviendas modestas y antiguas, sitas en inmuebles y barrios angostos y con frecuencia de relieve irregular. Por añadidura, para las edificaciones y equipamientos nuevos, por ignorancia, inercia y prurito de estilo, no se aprovechan plenamente las posibilidades del diseño accesible.

Aparte de la acción normativa y de vigilancia, los poderes públicos, especialmente las Comunidades Autónomas, prestan ayuda para la accesibilidad mediante convocatorias de subvenciones, es decir, en régimen discrecional. Los créditos afectados son, por lo demás, manifiestamente insuficientes para cubrir la demanda — sobre todo potencial— existente. 
Como se dirá después, el Sistema Nacional de Salud provee elementos ortoprotésicos en régimen de garantía de acceso a los mismos, mediante prescripción facultativa. Algunas ayudas técnicas no tienen reconocido carácter sanitario y la provisión pública de las mismas se realiza mediante régimen discrecional, aplicado por convocatorias de subvenciones de las Comunidades Autónomas principalmente. La distancia cuantitativa de los créditos a la demanda parece ser menor que en el caso de la supresión de barreras.

Es oportuno citar en este apartado el subsidio de movilidad y compensación por gastos de transporte creado por la Ley 13/1982, de 7 de abril, de integración social de los minusválidos. Se trata, obviamente, de un recurso supletorio de la accesibilidad pendiente.

La LEPA limita su cobertura de la accesibilidad y las ayudas técnicas a este precepto sobre ayudas discrecionales: "La Administración General del Estado y las administraciones de las Comunidades Autónomas podrán, de conformidad con sus disponibilidades presupuestarias, establecer acuerdos específicos para la concesión de ayudas económicas con el fin de facilitar la autonomía personal. Estas ayudas tendrán la condición de subvención...” (disposición adicional tercera).

Teniendo en cuenta los antecedentes reseñados, resulta obvio que esta disposición no aporta ningún compromiso nuevo. Por otra parte, según indica el Seminario de Intervención y Políticas Sociales (2008: 53), el régimen discrecional que establece supone un grave fallo de la integralidad proclamada en los artículos 1.2 y 3.c.

\section{Acción sanitaria}

La dependencia funcional demanda muy diversas e importantes intervenciones sanitarias. En primer lugar, las orientadas a evitar o minimizar las causas y factores de las enfermedades, traumatismos y deficiencias de las que pueden derivar situaciones de dependencia funcional. La prevención de la dependencia es objeto de valoración creciente en el medio sanitario, que postula al efecto tanto algunas medidas específicas como, sobre todo, las destinadas a muy diferentes riesgos de seguridad y de salud, sólo una parte de los cuales darían lugar a enfermedades y deficiencias generadoras de dependencia funcional. En segundo lugar y para ciertas situaciones de dependencia, cuidados especiales y modos especiales de prestar la atención sanitaria curativa y paliativa

La dependencia funcional, como la discapacidad en general, tiene como causa esencial la deficiencia psicobiológica, es decir, la alteración de estruc- 
turas anatómicas o de funciones psíquicas y biológicas (Organización Mundial de la Salud, 2001: 12 y 13). Por ello, y sin perjuicio de las circunstancias ambientales que pueden generar y agravar las limitaciones de actividad derivadas de las deficiencias, la rama sanitaria tiene un papel central en la prevención de las mismas y de la dependencia funcional que pueden originar: prevención primaria, actuando antes de que operen las causas (evitación de accidentes, vacunas, promoción de estilos de vida sanos, etc.); prevención secundaria, detectando tempranamente las enfermedades potenciales causantes de la dependencia y actuando sobre ellas (chequeos y tratamiento oportuno de enfermedades endocrinas, degenerativas, cardiovasculares, etc.); prevención terciaria, que se lleva a cabo mediante intervenciones curativas y rehabilitadoras cuando ya han ocurrido los traumatismos y las enfermedades de las que deriva la dependencia funcional (rehabilitación tras las reducciones de fracturas de cadera en personas de edad avanzada, por ejemplo). La rehabilitación, por cierto, incluye tratamientos y artilugios (prótesis, ortesis, ayudas técnicas).

Además de los tratamientos curativos aludidos que se practican en fase aguda, son necesarios algunos especiales cuando la dependencia se ha establecido (prevención y tratamiento de escaras en casos de inmovilidad, por ejemplo). También son necesarios en muchos casos de dependencia funcional procedimientos o recursos de asistencia sanitaria que superen las dificultades que entraña esa circunstancia para los modos comunes de dispensación de la misma. En esta faceta, la asistencia sanitaria tradicional disponía de dos modos comunes de atención propicios para situaciones de dependencia: la asistencia domiciliaria y la hospitalización indefinida. La vigente política de reducción drástica de estos modos asistenciales asume, al menos en el orden de las ideas, la necesidad de los mismos - aparte de otros alternativos - para ciertas situaciones de dependencia, en relación sobre todo con limitaciones de la capacidad asistencial de los familiares.

La Constitución Española reconoce el derecho a la protección de la salud (arts. 43 y 49), que fue objeto de la Ley 14/1986, de 25 de abril, General de Sanidad, por la cual se instituye el Sistema Nacional de Salud. Esta Ley adopta, de modo más explícito que sus precedentes, el enfoque de la salud pública en muchas de sus disposiciones (arts. 3, 6, 18, 19, 21). Y también opta por una orientación universalista (arts. 1 y 3). El Sistema Nacional de Salud asegura la provisión de una parte importantísima de las actividades colectivas y prestaciones individuales de carácter sanitario requeridas por la dependencia funcional; y lo hace en un régimen común para todo el país. 
La asistencia sanitaria pública garantizada por la Ley 14/1986, de 25 de abril, General de Sanidad fue regulada mediante el Real Decreto 63/1995, de 20 de enero, en cuyo Anexo I se relacionan las prestaciones sanitarias, facilitadas directamente a las personas por el Sistema Nacional de Salud y financiadas con cargo a la Seguridad Social o fondos estatales adscritos a la sanidad. Tras alcanzarse la plena financiación fiscal de la acción sanitaria, se promulga la Ley 16/2003, de 28 de marzo, de cohesión y calidad del Sistema Nacional de Salud, la cual regula un "Catálogo de prestaciones del Sistema Nacional de Salud" en el que integra estas nueve clases o modalidades de las mismas: "salud pública, atención primaria, atención especializada, atención sociosanitaria, atención de urgencias, la prestación farmacéutica, la ortoprotésica, de productos dietéticos y de transporte sanitario" (art. 7.1). El despliegue de ese catalogo se reglamentó mediante el Real Decreto 1030/2006, de 15 de septiembre, por el que se establece la nueva cartera de servicios comunes del Sistema Nacional de Salud. La misma abarca las modalidades o clases de prestaciones del catálogo, excepto la de "atención sociosanitaria". La tabla recoge algunas de las actividades colectivas y prestaciones individuales más relevantes para la prevención de la discapacidad y la atención en situaciones de dependencia funcional.

TABLA 2

\section{PRESTACIONES DE LA CARTERA DE SERVICIOS COMUNES DEL SISTEMA NACIONAL DE SALUD DE POTENCIAL INTERÉS PARA LA DEPENDENCIA FUNCIONAL}

\begin{tabular}{|l|l|}
\hline $\begin{array}{c}\text { MODALIDADES DE } \\
\text { INTERVENCIÓN }\end{array}$ & \multicolumn{1}{|c|}{$\begin{array}{c}\text { ACTIVIDADES O PRESTACIONES } \\
\text { (en cifra, las referencias que figuran en la norma) }\end{array}$} \\
\hline Salud pública & $\begin{array}{l}\text { Información y vigilancia epidemiológica (1) } \\
\text { Prevención de enfermedades y deficiencias (2.7) }\end{array}$ \\
\hline Atención primaria & $\begin{array}{l}\text { Prevención. Varias (3) } \\
\text { Prevención del desarrollo o de la progresión de trastornos } \\
\text { musculoesqueléticos (5.1) } \\
\text { Atención a la infancia: varias prestaciones de prevención y } \\
\text { atención temprana (6.1) } \\
\text { Atención del adulto, grupos de riesgo y enfermos crónicos: } \\
\text { atención domiciliaria a pacientes inmovilizados, prevención } \\
\text { para personas con conductas de riesgo (6.4) } \\
\text { Atención apersonas mayores: prevención, atención } \\
\text { domiciliaria a inmovilizados (6.5) }\end{array}$ \\
\hline
\end{tabular}




\begin{tabular}{|c|c|}
\hline $\begin{array}{l}\text { MODALIDADES DE } \\
\text { INTERVENCIÓN }\end{array}$ & $\begin{array}{c}\text { ACTIVIDADES O PRESTACIONES } \\
\text { (en cifra, las referencias que figuran en la norma) }\end{array}$ \\
\hline Atención especializada & $\begin{array}{l}\text { Hospital de día: Rehabilitación (2.2), ortoprótesis (2.4) } \\
\text { Hospitalización en internado: Rehabilitación (3.8) } \\
\text { Hospitalización a domicilio (4) } \\
\text { Procedimientos diags. y terapéuticos: Rehabilitación (5.3.4) } \\
\text { Servicios de prevención (5.3.9) } \\
\text { Rehabilitación en pacientes con déficit funcional } \\
\text { recuperable (8) }\end{array}$ \\
\hline $\begin{array}{l}\text { Prestación } \\
\text { orotoprotésica }\end{array}$ & $\begin{array}{l}\text { Implantes quirúrgicos (6) } \\
\text { Prótesis externas (7) } \\
\text { Sillas de ruedas (manual, eléctrica, accesorios) (8) } \\
\text { Ortesis (lecho postural, férulas, etc.) (9) } \\
\text { Ortoprótesis especiales (muletas de codo, guante con } \\
\text { protección, etc.) (10) } \\
\text { (Se prevé copago en varios casos) }\end{array}$ \\
\hline $\begin{array}{l}\text { Prestación de productos } \\
\text { dietéticos }\end{array}$ & $\begin{array}{l}\text { Nutrición enteral domiciliaria }(2.2) \text { para pacientes con } \\
\text { problemas de deglución, tránsito, trastornos neuromotores, } \\
\text { etc. (6.2) } \\
\text { (Se especifican las patologías subsidiarias de la nutrición } \\
\text { enteral domiciliaria en } 8 \text { ) }\end{array}$ \\
\hline Transporte sanitario & (Abarca al traslado entre comunidades autónomas: 4) \\
\hline
\end{tabular}

Fuente: Real Decreto 1030/2006, de 15 de septiembre.

Veamos ahora las carencias estructurales del Sistema Nacional de Salud, las cuales afectan a sus ámbitos subjetivo y material. El concerniente a este último es muy relevante para la dependencia funcional.

La orientación universalista de la Ley 14/1986, de 25 de abril, General de Sanidad se formula de modo explícito para la asistencia sanitaria pública (art. 3.2). Pero inicialmente la misma sólo sería plenamente accesible a la población con derecho a dicha protección por la Seguridad Social. Para la población sin ese derecho, la Ley 14/1986 posibilita el uso de los servicios sanitarios públicos, bien que en régimen privado (art. 16), salvo que para los carentes de recursos prevé una financiación mediante trasferencias estatales (art. 80) — distinta de la contributiva de la Seguridad Social que, a la sazón, soportaba la asistencia sanitaria de esta institución-. Mediante el Real Decreto 1088/1989, de 8 de septiembre, se extendió la cobertura de la asistencia sanitaria de la Seguridad Social a las personas sin recursos suficientes, con lo que se reconvierte la provisión de dicha prestación por la Beneficencia pública. 
Por la amplia cobertura resultante de las dos vías de acceso a la asistencia sanitaria pública y, también, por haber adoptado varias Comunidades Autónomas medidas de universalización plena en su ámbito, la carencia de protección subjetiva es pequeña: el 2,4\% de la población según la Encuesta Nacional de Salud 2006 (www.ine.es, 2006). Pese a su pequeña magnitud, no deja de ser oportuno señalar esta carencia, especialmente porque contrasta con importantes medidas de signo universalista relativas a la rama sanitaria. Por una parte, se le ha asignado naturaleza no contributiva, salvo para accidentes de trabajo y enfermedades profesionales (Ley General de la Seguridad Social, art. 86.2, según la modificación adoptada por la Ley 24/1997, de 15 de julio, de Consolidación y Racionalización del Sistema de la Seguridad Social - art. 1-). Por otra parte, la legislación de extranjería abrió la puerta de la asistencia sanitaria pública a la población inmigrante.

En lo que se refiere al ámbito material, la cartera de servicios regulada por el Real Decreto 1030/2006, de 15 de septiembre, trae consigo estimables ampliaciones de la garantía de cobertura, pero deben ser señaladas dos clases principales de fallos especialmente relevantes desde el punto de vista de la dependencia funcional. Por una parte, los especialistas echan de menos ciertos elementos en la "Prestación ortoprotésica" (Anexo VI). Por otra parte y según quedó indicado, se ha obviado la "Prestación de atención sociosanitaria". Para valorar su importancia respecto a la dependencia funcional, veamos cual es su contenido. La Ley 16/2003, de 28 de marzo, de cohesión y calidad del Sistema Nacional de Salud regula la "Prestación de atención sociosanitaria", que destina a "enfermos, generalmente crónicos, que por sus especiales características pueden beneficiarse de la actuación simultánea y sinérgica de los servicios sanitarios y sociales para aumentar su autonomía, paliar sus limitaciones o sufrimientos y facilitar su reinserción social" (art. 14.1). Dicha atención incluye "cuidados sanitarios de larga duración", "atención sanitaria de convalecencia" y "rehabilitación de pacientes con déficit funcional recuperables" (art. 14.2). Por otra parte, establece que "La continuidad del servicio será garantizada por los servicios sanitarios y sociales a través de la adecuada coordinación entre las Administraciones públicas correspondientes" (art. 14.3).

Los déficit de garantía de las prestaciones del Sistema Nacional de Salud pueden ser corregidos o salvados por estas dos vías, que regula la propia Ley 16/2003 (art. 20.2): 1) inclusión en la cartera de servicios del Sistema Nacional de Salud, previa aprobación por el Consejo Interterritorial del Sistema Nacional de Salud, lo que obliga a todas las Comunidades Autónomas; 2) libre asunción por las Comunidades Autónomas. Por supuesto, esta segunda vía entraña el riesgo de la desigualdad territorial, que está siendo 
grande en lo que concierne a los componentes de la "Prestación de atención sociosanitaria".

La acción sanitaria pública, además de desplegar sus medios en los escenarios comunes, lo hace también en otros sectoriales. Uno con especiales riesgos de enfermedades y accidentes que pueden abocar a la dependencia funcional es el laboral. Importa, pues, mencionar la acción sanitaria laboral. La norma pública vigente que corresponde a tal hecho $-\mathrm{y}$ que sigue una pauta internacional- es la Ley 31/1995, de 8 de noviembre, de Prevención de Riesgos Laborales. La misma impone la evaluación de riesgos para la seguridad y la salud de los trabajadores, así como la adopción de las medidas de prevención oportunas. Esta acción protectora, además de velar por la salud de los trabajadores, alcanza también a las situaciones de embarazo y maternidad reciente. Por ser menos conocida, parece oportuno recordar que esta línea de acción procura evitar riesgos relativos a aquel, al feto y a la lactancia. En pro de ello se establecen estas medidas preventivas: liberación del trabajo nocturno y por turnos, cambio de función o de puesto de trabajo en casos indicados, permisos para exámenes prenatales y preparación para el parto (art. 26).

Aun cuando fueron citadas en los apartados correspondientes, parece oportuno volver aquí sobre normas laborales y de Seguridad Social que contienen disposiciones destinadas a extender el alcance social de la prevención de riegos por embarazo y lactancia en el medio laboral. La Ley 39/1999, de 5 de noviembre, para promover la conciliación de la vida familiar y laboral de las personas trabajadoras introduce cambios (art. 10) en la regulación reseñada, entre los que destaca la posibilidad de suspensión del contrato por causa de riesgo durante el embarazo, enlazando con lo previsto en el Estatuto de los Trabajadores (Real Decreto legislativo 1/1995, de 24 de marzo, art. 45.1.d). Por otra parte, la citada Ley 39/1999 establece la inclusión en la Ley General de la Seguridad Social (título II, capítulo IV ter) de disposiciones que regulan una nueva prestación económica para el tiempo de suspensión del contrato por riesgo para el embarazo (art. 14). Dicha Ley 39/1999 modifica (art. 21) la Ley de funcionarios civiles del Estado en el sentido de incluir en la misma la licencia por riesgos durante el embarazo (Texto articulado aprobado por Decreto 315/1964, de 7 de febrero, art. 69.3). También introduce la Ley 39/1999 esa medida preventiva (art. 22) en la Ley 28/1975, de 27 de junio, sobre Seguridad Social de las Fuerzas Armadas (art. 21) y en la Ley 29/1975, de 27 de junio, de Seguridad Social, de los Funcionarios Civiles del Estado (art. 20). La Ley Orgánica 3/2007, de 22 de marzo, para la igualdad efectiva de mujeres y hombres introdujo, por una parte (disposición adicional duodécima), alguna modificación en el artículo 26 de la Ley 31/1995, de 8 de noviembre, 
de Prevención de Riesgos Laborales; por otra (disposición adicional decimoctava), extiende la prestación económica a la suspensión de contrato por riesgo durante la lactancia natural.

Las medidas de prevención de riesgos laborales son muy estimables. En el orden material, cabe recordar limitaciones como las siguientes: situaciones laborales irregulares, en las que no se aplica la legislación laboral y de Seguridad Social; situaciones laborales regulares pero inseguras en cuanto a reclamar la adopción de medidas de protección de la maternidad; situación económica personal o familiar en la que resulte problemática la merma de ingresos por el paso a la suspensión de contrato; desconocimiento de la normativa.

El Libro blanco preparatorio de la LEPA (Ministerio de Trabajo y Asuntos Sociales, 2004) contempló ampliamente la acción sanitaria relativa a la dependencia desde dos puntos de vista — por lo demás, conexos—: el de las prestaciones y servicios para las personas menores de 65 años afectas de dicha contingencia (cap. IV), y el de la atención al conjunto de las situaciones de dependencia por el sistema sanitario (cap. VI). En su capítulo conclusivo postula este contenido para la atención sanitaria a las personas en situación de dependencia: "los cuidados sanitarios de larga duración, la atención sanitaria a la convalecencia y la rehabilitación de pacientes con déficit funcional recuperable" (p. 765). La LEPA se apartó casi totalmente de la orientación francamente asumidora del Libro blanco en materia de acción sanitaria, así como de esta última propuesta. Veamos su contenido sanitario siguiendo el orden de su articulado.

La LEPA se inspira, entre otros, en el principio de colaboración de los servicios sociales y sanitarios (art. 3.l). En el orden de la aplicación, la Ley encomienda a las Comunidades Autónomas el establecimiento de los "procedimientos de coordinación sociosanitaria" (art. 11.1.c). Teniendo en cuenta la complejidad de esta empresa, según la experiencia acumulada durante muchos años, no parece plausible esa disposición meramente derivativa.

La primera rúbrica del catálogo de servicios de la LEPA incluye los de "prevención de las situaciones de dependencia" (art. 15.1.a). En el orden de la aplicación, la LEPA vuelve a derivar responsabilidades en las Comunidades Autónomas (art. 21). Como indica el Seminario de Intervención y Políticas Sociales (2008: 33-34): "La Ley 14/1986, de 25 de abril, General de Sanidad asigna al sistema sanitario funciones de prevención de las enfermedades y las deficiencias, incluyendo la rehabilitación (3.1, 6.3, 6.5, 18.2, 18.5 y 19), la cual abarca obviamente la dependencia. De este modo, las Comunidades Autónomas, por sus competencias y por las transferencias recibidas, tienen responsabilidades en prevención previas a la LEPA". 
La LEPA deja a salvo que los servicios de su catálogo "se regulan sin perjuicio de lo previsto en el artículo 14 de la Ley 16/2003, de 28 de mayo, de Cohesión y Calidad del Sistema Nacional de Salud" (art. 15.2). Se trata de un texto aparentemente vano, supuesto que, como quedó indicado anteriormente, la citada disposición reguladora de la "Prestación de atención sociosanitaria" no ha sido reglamentada, de modo que carece de eficacia asistencial. Y procede recordar al respecto que la exclusión de dicha prestación de la cartera de servicios del Sistema Nacional de Salud quedó formalizada el 15 de septiembre de 2006 - fecha del Real Decreto que aprueba aquella-, es decir, tres meses antes de que se aprobara la LEPA. Teniendo en cuenta la importancia de la "prestación de atención sociosanitaria" la doble omisión en la regulación de la garantía de acceso a la misma es de una gravedad obvia.

La LEPA dispone que "El servicio de atención residencial ofrece, desde un enfoque biopsicosocial, servicios continuados de carácter personal y sanitario" (art. 25.1). Siendo inmensa la gama de las atenciones sanitarias que demandan los usuarios de los servicios residenciales, resulta extraña esa indicación genérica.

\section{LOS SERVICIOS SOCIALES}

Las diferentes clases de funciones de los servicios sociales son relevantes para la dependencia funcional. Especialmente los públicos, están llamados a ejercer la prevención primaria de la discapacidad - y, por ende, de la dependencia-, como cualquier otro agente de bienestar con funciones de relaciones personales. Por supuesto, las actividades y prestaciones instrumentales de los servicios sociales públicos (prospección, diagnóstico, valoración, información orientación, etc.) abarcan la dependencia, como cualquier otra situación objeto de la rama. También son relevantes para el objeto de esta exposición las funciones activas (rehabilitación e inserción, principalmente). Por fin, las situaciones de dependencia requieren apoyos de mantenimiento, en lo que los servicios sociales están llamados a jugar un papel importante. Esto merece verse con algún detalle.

$\mathrm{Si}$ asumimos que a los afectados de dependencia funcional les conviene, en general, permanecer en su domicilio, el papel principal de los servicios sociales ha de ser posibilitarlo. Así pues, antes de hablar de residencias o medios similares de estancia permanente, veamos los medios o recursos de que disponen los servicios sociales para apoyar la permanencia en el domicilio: 
- La teleasistencia es un recurso para situaciones de riesgo; su utilización sin otros apoyos requiere que los usuarios tengan, salvo esas circunstancias de emergencia, capacidad para al menos las actividades básicas de la vida diaria: levantarse y acostarse, asearse, prepararse comida, etc.

- La llamada ayuda a domicilio se presta con frecuencia y contenido programados y debe poder abarcar, mediante uno o más agentes, tanto cuidados personales como ayuda doméstica; ésta puede consistir en la provisión exterior de comidas preparadas. En el plano del deber ser, ha de entenderse que la denominación servicio de ayuda a domicilio - $\mathrm{O}$ SAD — no limita sus prestaciones a las que se realizan dentro de la sede del asistido.

- Los centros de día y de noche sirven para proveer apoyos de duración diaria larga y ciertas prestaciones técnicas (terapia ocupacional, fisioterapia, terapia cognitiva, etc.). Algunos de ellos están especializados en determinadas afecciones causantes de dependencia, como la enfermedad de Alzheimer.

- Las estancias temporales o de respiro, necesarias para que los cuidadores familiares puedan atender necesidades propias y circunstanciales: vacaciones, enfermedades, viajes, etc.

Para los casos en los que la permanencia en el domicilio no está indicada o no resulta posible, ha de recurrirse a fórmulas residenciales alternativas a la domiciliaria: familias de acogida, viviendas tuteladas o compartidas y residencias asistidas para estancia continuada durante 24 horas. Estas últimas cuentan, por lo general, con algunos recursos sanitarios propios. Pero no son la misma cosa las residencias asistidas que los hospitales de media o larga estancia.

El régimen institucional de la oferta pública de los servicios sociales relativa a la atención a la dependencia presenta dos características muy relevantes para su eficacia protectora: la descentralización territorial y la carencia de garantía. La descentralización posibilita desigualdades territoriales. La carencia de garantía propicia la escasez y la precariedad de protección.

En lo que concierne al Estado (central), la Constitución le reserva la normativa básica y el régimen económico de la Seguridad Social (art. 149.1.17), competencia ésta que, salvo mejor interpretación, puede aplicar a sus Servicios Sociales. Sólo lo ha hecho para sustituir la financiación predominantemente contributiva por la fiscal. En cuanto al régimen de dispensación de las prestaciones y otras actividades, nunca fueron reguladas de modo que pudieran ser exigidas ante los tribunales, ni se le impusieron a la 
entidad obligaciones tasadas. Y así se ha transferido el grueso de los servicios del INSERSO — después, IMSERSO—a las Comunidades Autónomas.

Las Comunidades Autónomas tomaron competencia exclusiva en servicios sociales y promulgaron leyes reguladoras de los mismos. La mayor parte de dichas leyes no contemplan la dependencia funcional con esta denominación, pero en tales casos esa omisión queda suplida por el hecho de que dicho fenómeno hace parte de la discapacidad, que sí es objeto adoptado por todas aquellas. La Ley de Cantabria 6/2001, de 20 de noviembre, de Protección de las Personas Dependientes toma como objeto específico la dependencia genérica, es decir, no adscrita a alguna de las circunstancias personales, como la discapacidad o la edad avanzada. En los años siguientes, varias nuevas leyes generales de servicios sociales incluyeron la dependencia de modo explícito (GuILlÉn y VILÀ, 2007: 175); sin excepción las posteriores a la LEPA.

En cuanto a la cobertura de la dependencia funcional, todas las leyes regulan algunas prestaciones instrumentales (información, orientación, valoración, etc). El grueso de las mismas enuncia objetivos que cabe referir a la dependencia, como los de prevención, rehabilitación e integración, etc; si bien, por lo general, es muy defectuosa la regulación de las actividades o prestaciones correspondientes. En cuanto a prestaciones de asistencia de mantenimiento, una buena parte de las leyes no ofrece el repertorio completo. Pero, de todos modos, esa cortedad legislativa no ha sido obstáculo insalvable para que las administraciones competentes hayan desarrollado por vía reglamentaria la oferta de medios anteriormente reseñada.

El problema importante de las normas de servicios sociales promulgadas por las Comunidades Autónomas en relación con la dependencia proviene de que, con las excepciones de las más recientes que se indican más adelante, no garantizan las principales prestaciones individuales -ni las otras actividades- de servicios que regulan (CASAdo, 2002: 58-62). Desde hace muchos años se adoptan fórmulas que revelan la conciencia del problema pero no lo afrontaron de modo riguroso. La Ley 26/1985, de 27 de diciembre, de servicios sociales de Cataluña remitía la regulación de derechos de acceso a su reglamentación (art. 6); no se ha producido con carácter general. La Ley 5/1996, de 18 de octubre, (segunda) de servicios sociales de la Comunidad Autónoma Vasca fija un mínimo de prestaciones que van desde las actividades de objeto colectivo hasta la ayuda a domicilio y el alojamiento alternativo (art. 5.1), pero no regula el derecho que garantice el acceso a las mismas; el Decreto 155/2001, de 30 de junio, que desarrolla esa Ley, no salva el déficit, ya que impone a las Diputaciones la obligación de "garantizar la existencia de centros y servicios destinados a colectivos específicos, con capacidad suficiente para responder a las necesidades de la población" (art. 3.1), pero tampoco 
regula el derecho de acceso de los interesados. La Ley 1/2003, de 24 de febrero, (segunda) de Servicios Sociales del Principado de Asturias prevé un catálogo de prestaciones, en el que se especificarán las exigibles como derecho subjetivo (art. 20.2) y fija un plazo al efecto de dos años (disposición adicional segunda); se ha rebasado sin cumplir el mandato legal. La Ley 11/2003, de 27 de marzo, (segunda) de Servicios Sociales de la Comunidad de Madrid, declara "universales y gratuitas para toda la población" las que denomina "prestaciones técnicas" (art. 19.2), que consisten en información, orientación, tutela jurídica y semejantes, y que excluyen las prestaciones individuales con empleo intensivo y/o continuado de recursos (ayuda domiciliaria, asistencia en centros de cuidados diurnos, servicios residenciales, etc.).

Importa recordar, por otra parte, que las leyes de servicios sociales asignan a los Corporaciones locales - Ayuntamientos principalmente- competencias relativas a la atención primaria. Por lo que se refiere a la dependencia funcional, la misma incluye buena parte de las prestaciones instrumentales, así como la teleasistencia y la ayuda a domicilio. Esta capacidad que se asigna al nivel local no va acompañada de medidas para exigir su desempeño con garantía de protección para los ciudadanos —ni financiación que lo posibilite, aducen los responsables locales-.

La carencia de garantía permite, en primer lugar, la adopción de elencos de oferta diferentes para los distintos territorios. Tal posibilidad está dando lugar a disparidades muy graves. En segundo lugar, la discrecionalidad hablita a los agentes para racionar la oferta de las prestaciones que dispensan. Lo cual se está practicando, sobre todo, con las prestaciones caras, como son las relativas a la asistencia de mantenimiento de la asistencia. Para administrar la escasez, las administraciones públicas gestoras de los servicios sociales vienen recurriendo a la aplicación de baremos relativos, no sólo a las necesidades técnicas, sino también a la situación social y económica de los demandantes -o de sus familias-. Mediante los mismos, para el caso de la dependencia, se discriminan los casos que reciben mejor atención de sus familiares y los de rentas medias - los de rentas altas no suelen solicitar plazas públicas- . De este modo, se niega de hecho la condición universalista de los servicios sociales que sus leyes reguladoras proclaman, a la vez que marginan a demandantes de clases medias cuya capacidad para adquirir prestaciones sociales mercantiles no se comprueba. Por lo demás, la citada técnica, propia de la Beneficencia pública, estigmatiza a los servicios sociales del sector público en el mismo sentido que los estigmatizó el régimen benéfico —es decir, como servicios para pobres - y los inhabilita así para cumplir el papel -análogo a los de la asistencia sanitaria, la educación y las prestaciones económicas del sector público- que están llamados a desempeñar en un Estado 
social moderno. Las circunstancias indicadas influyen de modo diferente en la oferta de prestaciones relativas a la dependencia.

El objetivo de la prevención primaria de la discapacidad — que incluye la dependencia - no ha sido objeto de formulación ni de programación autónoma. Dejando a un lado la cuestión de si es propio de los servicios sociales, procede señalar que algunos órganos gestores de los mismos realizan actividades que tienen dicha función de prevención primaria; tal es el caso de las actividades culturales y de ocio para personas de edad avanzada.

Las actividades y prestaciones instrumentales de carácter general de los servicios sociales públicos se vienen ofertando de modo desigual. Las prestaciones de diagnóstico, valoración, información y orientación son provistas por los servicios sociales de atención primaria y por ciertos equipos de valoración especializados al común de quienes las demandan de modo gratuito. La prospección proactiva, tan importante para las situaciones de dependencia, apenas se practica.

Parece que la mayor parte de las aportaciones de los servicios sociales a la rehabilitación y la integración de las personas en riesgo o afectas de dependencia se realizan actualmente haciendo parte de la atención en centros de día y residencias. Su oferta, por la descentralización y la discrecionalidad características de los servicios sociales públicos, es muy dispar desde el punto de vista territorial.

La oferta de las prestaciones de apoyo a la permanencia en el domicilio gestionadas - de modo directo o, más frecuentemente, indirecto- por los Ayuntamientos — teleasistencia y ayuda a domicilio principalmente, según quedó indicado - es harto dispar de unos lugares a otros: en algunos casos no se ofrecen; en la mayoría la cobertura es escasa. Para la ayuda a domicilio, esa escasez deja fuera a muchos solicitantes, lleva aparejadas unas tarifas de copago elevadas y es pobre en cuidados personales. Los organismos públicos - por lo general, las Administraciones de las Comunidades Autónomasmantienen una oferta de centros de día muy inferior a la demanda, con un efecto de exclusión análogo al de la ayuda a domicilio. Las insuficiencias de la oferta pública de apoyos para la permanencia en el domicilio, además de entrañar descobertura, traen consigo el efecto indirecto de estimular la demanda de recursos residenciales, más caros y, en general, menos deseables desde el punto de vista del bienestar.

De las diferentes fórmulas sustitutorias del domicilio propio, las residencias ocupan la inmensa mayoría de la oferta. Según muestran las listas de espera, las disponibilidades de plazas públicas - nuevamente, de gestión directa y contratada o concertada - son insuficientes. Para valorar este hecho debe tenerse en cuenta que la escasez de medios de apoyo a la permanencia en el domicilio parece generar un plus de demanda de plazas residen- 
ciales. (La oferta de las mismas del régimen mercantil viene creciendo con fuerte ritmo, lo cual está dando lugar ya a excesos de oferta - a los precios de mercado- en ciertos lugares). Resulta oportuno recordar que la atención residencial no debería suponer en modo alguno la segregación del medio comunitario. Incluso las residencias asistidas deben situarse, no en parajes campestres y lejanos, sino en el interior de las núcleos urbanos, abiertas a la comunidad. Conviene mejor a la idea de integración de los residentes que el tamaño sea pequeño. En cuanto al régimen, debe favorecerse la presencia y colaboración de familiares, amigos y voluntarios. El grueso de nuestra oferta residencial se aparta grandemente de estos criterios.

Las situaciones de necesidad más graves sufren discriminación en los regímenes de discrecionalidad con escasez de oferta, por su menor tolerancia a las demoras derivadas de las listas de espera. Las situaciones de dependencia de la población con menos recursos económicos, por sus obvias limitaciones para acceder a los servicios mercantiles, gravan más acusadamente sobre las familias cuidadoras, lo que puede redundar en perjuicio de la calidad de los cuidados y, por supuesto, en costes de oportunidad y estrés para los cuidadores. Como ya quedó dicho, la dificultad de acceso a la protección puede llegar a ser especialmente grave y aun absoluta para la teleasistencia y la ayuda a domicilio, prestaciones asignadas a los Ayuntamientos.

Cabría pensar que las deficiencias de la oferta pública de servicios sociales para la dependencia, especialmente en lo relativo a la asistencia de mantenimiento, moverían fuertes presiones de la población que soporta esa función mediante recursos propios o de familiares. Por lo que atañe a las Comunidades Autónomas, parece que viene dominando la tolerancia social e incluso de los especialistas a la contradicción del intenso celo competencial de aquellas en materia de servicios sociales con su tibieza y aun negligencia para garantizar el acceso a los mismos. Si alguien denuncia este hecho suele invocarse por los aludidos la escasa dotación que reciben las Comunidades Autónomas de la Hacienda central para esa aplicación. Ante este rutinario recurso exculpatorio, procede recordar circunstancias como las siguientes. Las Comunidades Autónomas, al tomar competencia exclusiva en servicios sociales, asumieron la responsabilidad de afrontar la más que previsible evolución creciente de la demanda social de los mismos. En otro orden de cosas, las aplicaciones de los créditos de la Administración General del Estado a las Comunidades no están vinculadas de manera rígida. Las mismas complementan los ingresos procedentes de la Hacienda central con los ingresos propios por tasas y contraprestaciones de servicios. Y pueden crear otros gravámenes propios. Para casos determinados cabría pensar incluso que sobra financiación, visto que practican o pretenden practicar la munificencia de dispensar prestaciones monetarias ocasionales o no y graciables; como 
ciertos complementos monetarios a las prestaciones nacionales de esa clase. En lo se refiere a la dependencia funcional, cabe decir que las iniciativas de las Comunidades Autónomas apuntadas antes parece que fueron más fruto de libre decisión que de presiones sociales. Y se viene tolerando igualmente, tanto por la opinión común como por la ilustrada, la inacción jurídico-política del Estado (central) en cuanto a los Servicios Sociales de la Seguridad Social. También para este ámbito procede decir que fueron fruto de iniciativas no derivadas de presiones exteriores los estudios sobre la mejora de la protección relativa a la dependencia iniciados hace un decenio por el IMSERSO (Rodríguez Cabrero [coordinación], 1999).

La LEPA opta muy principalmente por los servicios sociales para su acción protectora (art. 14.2). Y, según muestra el catálogo de los mismos, la mayor parte de sus componentes son servicios sociales de asistencia de mantenimiento (art. 15.1):

- "Servicios de prevención de las situaciones de dependencia y los de promoción de la autonomía personal"

- "Servicio de teleasistencia"

- "Servicios de ayuda a domicilio", que abarca cuidados domésticos y personales

- "Servicio de Centros de Día y de Noche", los primeros con estas especialidades: mayores, menores de 65 años y de atención especializada

- "Servicio de atención residencial", para "mayores" y "en razón de distintos tipos de discapacidad".

Los servicios de prevención incluidos en la primera clase del catálogo son objeto de una mínima regulación por la propia Ley (art. 21), la cual: les señala la "finalidad de prevenir la aparición o el agravamiento de enfermedades o discapacidades y sus secuelas"; los encomienda a los servicios sociales y de salud, en coordinación; les asigna "actuaciones de promoción de condiciones de vida saludables, programas específicos de carácter preventivo y de rehabilitación"; los destina "a las personas mayores, personas con discapacidad y a quienes se ven afectados por procesos de hospitalización complejos"; finalmente, remite la concreción de la acción preventiva a Planes de las Comunidades Autónomas, que habrán de atenerse a los criterios que adopte el Consejo Territorial del Sistema para la Autonomía y la Dependencia. Según se indica el Seminario de Intervención y Políticas Sociales (2008: 33-34): "El objetivo de 'prevenir la aparición' de las situaciones de dependencia desborda el título de la LEPA y, lo que es más relevante, su ámbito subjetivo, que se limita a los afectados por la misma (art. 5.1.a). Por el interés sustantivo de la acción preventiva, cabe dar la bienvenida a la indicada 
anomalía, salvo que habrá de esperarse a la formulación de los Planes que prevé el artículo 21 para conocer la utilidad de la misma." Hecha esta salvedad y en relación con el contexto de medidas públicas reguladas previamente, procede preguntarse que añadirán tales planes a las amplias responsabilidades en la función preventiva que, según quedó indicado, asigna la normativa sanitaria al Sistema Nacional de Salud.

Los servicios de promoción de la autonomía funcional, segundo componente de la primera rúbrica del catálogo, no es objeto de regulación en la LEPA. Se ha suplido esta omisión en el desarrollo de la misma (Seminario de Intervención y Políticas Sociales, 2008: 35)

Los servicios de teleasistencia, ayuda a domicilio, centros de día y de noche, y de atención residencial son habituales, según quedó indicado, en la oferta de los servicios sociales públicos. La regulación de este bloque en su aspecto técnico (arts. 22 a 25) no aporta novedades. Si acaso abunda en algunos defectos de la normativa previa de las Comunidades Autónomas. El Seminario de Intervención y Políticas Sociales (2008: 29) indica estos dos relativos al conjunto: 1) el catálogo no identifica prestaciones técnicas de aplicación individual, sino programas (teleasistencia, ayuda a domicilio) o centros contenedores de aquellas; 2) el catálogo omite prestaciones de apoyo individualizado para facilitar el acceso y la buena relación con la acción protectora, como sería la gestión de caso. La novedad clave de la LEPA en esta parte de su contenido prestacional concierne a su régimen de acceso. Las Comunidades Autónomas, como quedó dicho, venían ofertando tales servicios discrecionalmente; la LEPA regula el derecho subjetivo a los mismos (art. 1.1), bien que sólo garantiza determinados contingentes de recursos protectores (arts. 7, 9 y 10).

La LEPA establece que la prestación de los servicios de su acción protectora se realizará a través de la "oferta pública de la Red de Servicios Sociales por las respectivas Comunidades Autónomas...” (art. 14.2) — nótese y quede a un lado la omisión de los servicios sanitarios- - Y, para salvar los casos de imposibilidad de que esto se lleve a efecto, la Ley instituye la prestación económica vinculada al servicio (arts. 17), es decir, afectada a la financiación de prestaciones técnicas adquiridas fuera de la red pública. La LEPA se atiene a la consistencia material de esta prestación para clasificarla como económica, pero su afectación obliga a mencionarla en la reseña de los servicios sociales.

Por las circunstancias presentes y probables de la oferta pública, la prestación económica vinculada al servicio resulta muy oportuna. Y por la estimación que se ha hecho de la misma por partes interesadas, es obligado cuestionar el acceso restringido que establece la Ley. El mismo es contradic- 
torio, por lo demás, con el principio de autonomía que proclama (art. 3.h).

La LEPA entraña un gran potencial de impacto en las estructuras públicas relativas a los Servicios Sociales (Guillén y Vilà, 2007: 177 y ss.): primero, en razón de que supone un incremento cuantitativo de la oferta; segundo, porque el régimen jurídico de sus prestaciones garantizadas lleva criterios de concesión y procedimientos nuevos. Las Comunidades Autónomas han llevado -y siguen llevando- a cabo diferentes maniobras para integrar o yuxtaponer la línea protectora de la LEPA. Y algunas de ellas han recibido el impacto en sus nuevas leyes de servicios sociales. La Ley foral 15/2006, de 14 de diciembre, de Servicios Sociales, de Navarra, elaborada y aprobada paralelamente a la LEPA, acusa recibo explícitamente de sus previsiones. Así, establece la inclusión en la cartera de servicios garantizados la "atención domiciliaria municipal” (art. 20); y crea un Programa de Promoción de la Autonomía Personal y Atención a las Personas en situación de Dependencia (art. 31.1.b). La Ley de Cantabria 2/2007 de 27 de marzo, de Derechos y Servicios Sociales declara en su preámbulo (II) que se inspira en la iniciativa estatal de "reconocimiento del derecho a la promoción de la autonomía personal y a la prevención y protección de las situaciones de dependencia”. En esa línea, instituye la Ley el derecho subjetivo universal a una cartera de servicios, en la que se incluyen, entre otros, los de asistencia de mantenimiento para las situaciones de dependencia que hacen parte del catálogo de la LEPA (arts. 4.1 y 27.1.A). La Ley 12/2007, de 11 de octubre, de Servicios Sociales de Cataluña muestra la recepción del movimiento de ideas relativas a la dependencia en su Catálogo clasificado de servicios y prestaciones sociales (anexo). Uno de sus apartados corresponde a "Personas mayores con dependencia o riesgo social" (1.2.2). Dentro del correspondiente a personas con discapacidad (1.2.3), se incluye el "Servicio de valoración de la dependencia” (1.2.3.1.1).

\section{BIBLIOGRAFÍA Y FUENTES}

Alonso Seco, José María y Gonzalo González, Bernardo (1997), La asistencia social y los servicios sociales en España, Madrid, Boletín Oficial del Estado.

Aznar López, Manuel (1999), "La protección social de la dependencia en España (legislación del Estado)”, en Rodríguez Cabrero, G. (coordinación), La protección social de la dependencia, Madrid, Ministerio de Trabajo y Asuntos Sociales, pp. 175-344.

Casado, D. (2002), Reforma política de los servicios sociales, Madrid, Editorial CCS.

Guillén, Encarna y VILÀ, Antoni (2007), "Los cambios legislativos recientes en materia de servicios sociales", en Casado, Demetrio y Fantova, Fernando (coordinadores), Perfec- 
cionamiento de los servicios sociales, Informe con ocasión de la Ley sobre autonomía y dependencia, Madrid, Caritas Española Editores.

Guillén, Encarna y Vilà, Antoni (2007), "Impacto de la Ley de Promoción de la Autonomía Personal y Atención a las personas en situación de dependencia en los servicios sociales de las Comunidades Autónomas", en Casado, Demetrio y Fantova, Fernando (coordinadores), Perfeccionamiento de los servicios sociales, Informe con ocasión de la Ley sobre autonomía y dependencia, Madrid, Caritas Española Editores.

Instituto Nacional de Estadística (2006), Encuesta Nacional de Salud 2006, www.ine.es.

Ministerio de Trabajo y Asuntos Sociales (2005), Atención a las personas en situación de dependencia. Libro blanco, Madrid.

Organización Mundial de la Salud (2001), Clasificación Internacional del Funcionamiento, de la Discapacidad y de la Salud, Instituto de Migraciones y de Servicios Sociales, Madrid.

Rodríguez Cabrero, Gregorio (coordinación) (1999), La protección social de la dependencia, Ministerio de Trabajo y Asuntos Sociales.

Rodríguez Cabrero, Gregorio, (2004): "La población dependiente española y sus cuidadores", en Casado, Demetrio. (dir): Respuestas a la dependencia, Madrid, Editorial CCS.

Rodríguez Márquez, J. y Ruiz Hidalgo, C. (2004), La protección de las personas discapacitadas a través del ordenamiento tributario, Madrid, Ministerio de Trabajo y Asuntos Sociales.

Rodríguez Rodríguez, Pilar (2006), El sistema de servicios sociales español y las necesidades de la atención a la dependencia, Madrid, Fundación Alternativas

Seminario de Intervención y Políticas Sociales (SIPOSO) (2008), Anotaciones a la LAAD, Madrid, Polibea.

VILÀ, Antoni (2004), "Estructuras institucionales de la protección social de la dependencia funcional", en Casado, Demetrio (dir.), Ante la dependencia, Madrid, Editorial CCS. 